\title{
Statistics of Dangerous Cargo Accidents during Highway Transportation
}

\author{
Xiao $\mathrm{Li}^{1}$, Yong Liu ${ }^{1,2 *}$, Linsheng Fan ${ }^{1}$, Minghui $\mathbf{Q i}^{1}$, Tao Zhang ${ }^{1}$ \\ 1. School of Resource Environment and Safety Engineering, Hunan University of Science and Technology, \\ Xiangtan, Hunan 411201, China \\ 2. Work Safety Key Lab on Prevention and Control of Gas and Roof Disasters for Southern Coal Mines, Hunan \\ University of Science and Technology, Xiangtan, Hunan 411201, China \\ *Corresponding Author.
}

\begin{abstract}
Research on present situation and trends of accidents takes an important role on prevention and control on dangerous cargo accidents during highway transportation. According to the current situation of highway transportation for dangerous cargo, the characteristics of highway transportation system for dangerous cargo are put forward. Statistical analysis of dangerous cargo in China from 2013 to 2019 related to characteristics and consequences are discussed in this study. The different time volatility, spatial distribution and accident consequence features are revealed. Results show that the dangerous cargo of highway transportation system presents a multiple spots, long lines, broad coverage, and high risk features. The annual scale of dangerous cargo accidents shows irregular ' $M$ ' distribution since 2013. December is the month with the most accidents. Wednesday is the day with the most accidents. Fifth period is the most accidents. Shandong is the province with the most accidents. Normal section is the section with the most accidents. The liquid is the type with the most accidents. Leakage is the most common type of accident. Countermeasures focusing on improving highway transportation safety for dangerous cargo accidents are recommended.
\end{abstract}

Keywords: Dangerous cargo, highway transportation, accidents, statistical analysis

\section{Introduction}

By the end of 2018, there were 123,000 highway transportation enterprises for dangerous cargo, 373,000 vehicles and 1.6 million employees in China [1]. The volume of dangerous cargo during highway transportation accounted for $70 \%$ of the total volume of transport for dangerous cargo (http://www.xinhuanet.com/fortune/201812/03/c_1123797125.htm). More than 1 billion tons of hazardous materials are transported by road each year, accounting for more than 30 per cent of total annual volume during highway transportation, and shows an upward trend (http://www.sohu.com/a/123466612_473276, http://www.zgsyb.com/html/content/201802/23/content_799236.shtml). Once the hazardous materials of inadequate protection or disposal, it is easy to cause accidents. Dangerous cargo accidents occur frequently during highway transportation. Of course, there are some severe and very serious accidents of dangerous cargo [2-3]. On 28 June 2018, in Shibalipu Town, Yingshang County, Fuyang City, Anhui Province, the rear-end of isooctane tank tanker caused an explosion accident, resulting in 8 deaths and 3 injuries, with direct economic losses of more than 10.51 million yuan. On June 13, 2020, an explosion occurred on the side of a liquefied petroleum gas tank truck at the Wenling export of Taizhou, Zhejiang Province, on the G15 Shenhai Expressway, resulting in the death of 20 people and the collapse of some houses and workshops around them. These cases show that the consequence of dangerous cargo accidents during highway transportation is serious, threatening people's lives and property safety and traffic safety. Therefore, in order to prevent and control dangerous cargo accidents during highway transportation effectively, it is necessary to grasp the present situation and laws of dangerous cargo accidents during highway transportation.

ISSN: 0010-8189

(C) CONVERTER 2021

www.converter-magazine.info 
The research on the risk and regularity of dangerous cargo accidents during highway transportation has been paid much attention all over the world. The US Pennsylvania road traffic accident database for dangerous cargo is used to analyze the impact of accident factors such as accident causes, types of dangerous cargo and road types [4]. Aiming to explore systematic ways to address the problem of how many accidents involving hazardous materials actually occur in Europe, a framework for predicting the total accident amount was therefore developed and applied based on 535 unique accident descriptions from seven accident databases covering the nine-year period from 1984 to 1992 [5]. Accident probabilities under different road types and vehicle conditions during UK highway transportation of dangerous cargo are counted. Methodologies for assessing the extent of remedial measures needed to make a shorter road fit for the transport of dangerous goods (DGT) were proposed [6]. Data of highway transportation accidents of dangerous goods in Korea from 2008 to 2016 are used to study the influencing factors of vehicle collision accidents of dangerous goods [7]. Additional results of research regarding how involved parties in Estonia evaluate possible harms resulted by their activities while handling and transporting DG confirm the main finding that human factor is one of the crucial factors why accidents occur [8]. By using association rule mining method, the highway transportation accident data of dangerous cargo in Korea from 2008 to 2017 were used to study the influencing factors of dangerous cargo vehicle collision accidents [9]. In the past period, the transportation accidents of hazardous chemicals in different periods in China have also been counted from the aspects of accident category, road grade, road section characteristics and time [10]. However, the statistical sample space of highway transportation accident data of dangerous cargo studied in the past is small and lack of accident data in recent years [11-12]. This paper collects 2335 dangerous cargo accidents during highway transportation in China from 2013 to 2019, and studies on the characteristics of highway transportation system of dangerous cargo, the present situation which includes the temporal and spatial distribution and accident consequence characteristics of highway transportation accidents for dangerous cargo is discussed.

\section{Characteristics of Highway Transportation System for Dangerous Cargo}

There are 2828 categories of hazardous materials listed in the Inventory of Hazardous Chemicals (2015 Edition) at home, and a total of 8 categories and 21 items are involved according to their main hazard classification. Hazardous materials with different properties such as poison, corrosion, explosion, combustion, and combustionsupporting have been widely used. In the transportation process of hazardous materials, once they are improperly protected and used, they can easily endanger the safety of human bodies, facilities and the environment [13]. In particular, transportation accidents of hazardous materials occur in crowded areas, important facilities, and key locations, which are more likely to cause heavy casualties. Such as Jinji Expressway Yanhou Tunnel ' 3.1 ' Extraordinary Road Traffic Hazardous Chemicals Explosion Accident, Shanghai-Kunming Expressway '7.19' Extraordinary Road Traffic Hazardous Chemicals Explosion Accident, Zhangshi Expressway Futuyu No.5 Tunnel The '5.23' Major Explosion Accident has brought to endanger biggest. Hazardous materials and their accident consequences, which are characterized by 'broad coverage' and 'high risk', need to be focused on prevention and control during transportation and the other link.

Transport vehicles of hazardous materials are the transport carriers for dangerous cargo which go back and forth between the production, storage, use and operation of hazardous materials, realize the operation and circulation of hazardous materials [14,15]. According to statistics from the Traffic Management Bureau of the Ministry of Public Security, as of the end of June 2020, the volume of transport vehicles for hazardous materials in China has reached 604,000. Many transportation vehicles are scattered all over the country, and the geographical location of dangerous cargo vehicles has the characteristic of 'multiple spots'. In the same period, the total mileage of highways reached 5.0125 million kilometers, of which the mileage of secondary and above grade highways was 672 thousand kilometers, and the mileage of expressways was 149,600 kilometers (http://www. mot.gov.cn/2020zhengcejd/hangyetjgb_2019/,). Dangerous cargo transportation vehicles traverse north-south and pull east-west on the longitudinal highway network, forming a trajectory characterized by 'long lines'.

ISSN: 0010-8189

(C) CONVERTER 2021

www.converter-magazine.info 
Therefore, the dangerous cargo system of highway transportation presents a multiple spots, long lines, broad coverage, and high risk features.

\section{Methodology}

The safety of dangerous cargo during highway transportation in China is under the joint supervision of multiple departments. According to the Measures for the Safety Management of Highway transportation of Dangerous cargo, the competent department of transportation is responsible for issuing licenses for highway transportation of dangerous cargo and supervising and inspecting highway transportation enterprises of dangerous cargo. The competent departments of industry and information technology shall deals with the production enterprises of dangerous cargo transportation vehicles according to law, carry out supervision and inspection, investigate and punish production enterprises and products that violate laws and regulations. Public security organs are responsible for the issuance of road transport permits for highly toxic chemicals, civilian explosives, fireworks and firecrackers, and radioactive transport permits or documents, and are responsible for the order management of dangerous cargo transport vehicles. The competent department of ecology and environment supervises and inspects the design, manufacture and use of radioactive material transportation containers. The emergency management department and other departments with the responsibility of safety production supervision and management are responsible for the supervision of the production, storage, use and operation of hazardous chemicals in accordance with the law. The market supervision and management department is responsible for investigating and punishing the illegal behaviors of hazardous materials and the tank body quality of atmospheric tank vehicles and the behavior of the tank body inspection agency of atmospheric tank vehicles issuing false inspection certificates. In addition, the transportation management department also undertakes the management of dangerous goods transportation lines and transportation stations, the maintenance of dangerous cargo transportation vehicles, comprehensive performance testing, the training and management of motor vehicle drivers and escorts, road maintenance, road administration, operation management and road marking management. Emergency management department fire rescue agencies are also responsible for highway transport accidents of dangerous goods emergency rescue. The public security organs are responsible for the examination of motor vehicle drivers and the inspection of driving licenses. For highway transportation accidents of dangerous cargo under multiagency supervision, there is no clear statistical focal point and statistical caliber for the time being. Therefore, data on dangerous cargo accidents during highway transport can only be obtained through the news report and Internet.

Obtaining data is an important prerequisite and guarantee for carrying out accident statistical analysis. There are two important factors which affect the acquisition of accident data. One is data sources and the other one is data processing methods. These factors directly affect the authenticity, completeness and operability of data acquisition. Dangerous cargo accident date of highway transport is mainly obtained through the following three ways. Firstly, the petrochemical accident analysis and data interpretation platform, operated by the Chemical Safety Net of the Chemical Registration Center of the Ministry of Emergency Management, released the production, operation, storage and transportation since 2012 And other chemical accidents. The second one is the website of the Ministry of Emergency Management, including the former State Administration of Work Safety's accident inquiry platform and the Ministry of Emergency Management's disaster accident information platform, which release investigation reports on major accidents including chemical accidents. The third one is the China Hazardous Chemicals Logistics Network, operated by the Hazardous Chemicals Logistics Branch of the China Federation of Logistics and Purchasing, which publishes accidents in the logistics and transportation of hazardous chemicals at home and abroad.

The web crawler software 'Octopus' (V7.6.4.4281 version) is used to collect dangerous cargo accident data of highway transportation. Using the 'custom' mode to establish information collection scripts for three different accident source web pages, by scripts debugging, Web crawling, and data export, then a web page information

ISSN: 0010-8189

(C) CONVERTER 2021

www.converter-magazine.info 
collection model was created. In view of the incomplete record of accident data before 2013, this article only counts the dangerous cargo accidents which occurred from January 1, 2013 to December 31, 2019. Through manual checking of the collected 4488 accident information, and cleaning of invalid, missing and duplicate data, the information on 2335 dangerous cargo accidents during highway transportation was finally determined.

\section{Situation of Dangerous Cargo Accidents during Highway Transportation}

The situation of dangerous cargo accidents during highway transportation is analyzed, including the time distribution, space distribution and consequences.

\subsection{Time characteristics of accidents}

According to the 2,335 highway transportation accidents of dangerous cargo in different years, the annual distribution map of the accident amount for dangerous cargo during highway transportation is shown.

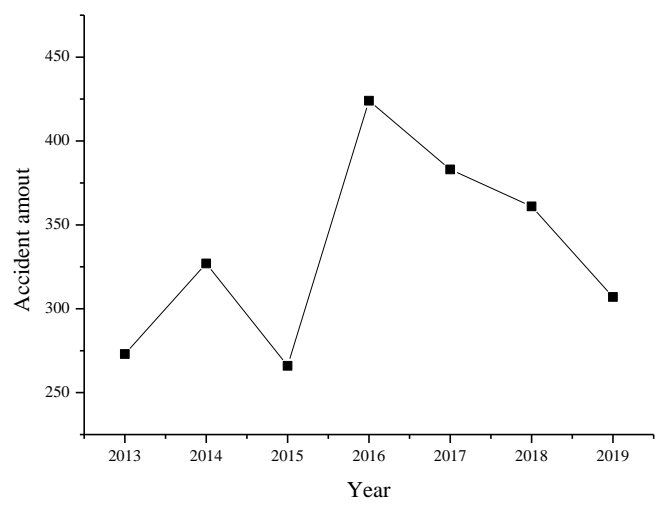

Fig 1: Annual characteristic of accident

As figure 1 shown, the trend of annual accident amount for dangerous cargo in China was an irregular ' $M$ ' distribution since 2013. The accident amount for dangerous cargo increased first and then decreased and then increased and decreased year by year. Among them, the dangerous cargo accident occurred the least in 2015. Most accidents occurred in 2016, and then the accident scale decreased year by year.

The accident amount of dangerous cargo was related to the intensity of supervision and management of road transport safety of dangerous cargo. In 2014, there were two particularly significant dangerous cargo accidents during highway transportation in succession. One was the explosion accident for 3.1 Shanxi Jinji highway rock tunnel methanol and the other one was fire accident for 7.19 Hunan Hukun highway Shaoyang ethanol. Then, a number of regulations and documents to carry out special rectification activities were issued jointly by the Ministry of Transportation and State Administration of Work Safety. Therefore, the dangerous cargo accident amount during highway transportation fell sharply. Later, due to the relaxation of safety supervision after the remediation activities, the amount of dangerous cargo accidents of in 2016 increased sharply. After the second half of 2016, policy documents such as Evaluation and Management of Safety Production Standardization Construction in Transportation Enterprises and In-depth Development of Special Rectification Action Plan for Safe Traffic were successively issued, causing the accident amount to reduce from 2017. Therefore, administrative supervision has obvious intervention in the safety situation of highway transportation of dangerous cargo, which reflects that the safety subject responsibility of Chinese highway transportation enterprises of dangerous cargo needs to be further implemented.

ISSN: 0010-8189

(C) CONVERTER 2021

www.converter-magazine.info 
According to the monthly trend and weekly trend of the dangerous cargo accidents during highway transportation, 2335 accidents are counted. The monthly and weekly distribution maps of accident amount for dangerous cargo are obtained.

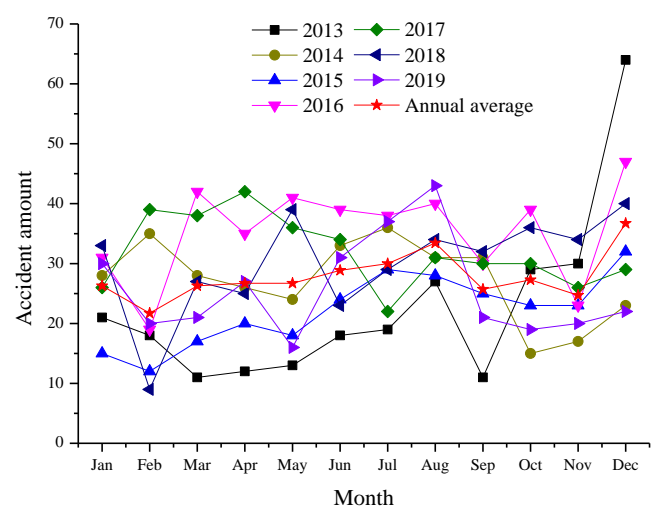

Fig 2: Monthly characteristics of accidents

As shown in figure 2, the dangerous cargo accident amount during highway transportation occurred monthly from 2013 to 2018 fluctuated within the range of $[8,70]$. From the perspective of annual average, February was the month when the dangerous cargo accidents occurred least. The accident amount remained at a high level between March and August. From September to November, the accident amount decreases slightly. The dangerous cargo accidents highway transportation occurred most in December, followed by August.

The occurrence of dangerous cargo accidents during highway transportation is closely related to the highway transportation capacity of dangerous cargo, which is mainly affected by the Chinese Spring Festival, Mid-Autumn Festival and National Day. The Spring Festival is generally in February. During the nearly 40 days Spring Festival holiday from mid to late January, dangerous cargo vehicles are prohibited from entering the highway. This makes the demand of each hazardous chemical user for raw materials concentrated in December and January, resulting in large transportation volume and accident scale in previous two months. In addition, the National Day and MidAutumn Holidays generally take place in October when the demand for hazardous materials users and the capacity of hazardous materials producers decreased, thus affecting the volume of highway transportation and accident amount prior to September and subsequent November. This reason is basically consistent with the Analysis Report on the Operation of National Highway Network during the Spring Festival in 2018 analysis released by the Highway Bureau of the Ministry of Transport (http://sh.bendibao.com/traffic/ 2018131/189992.shtm).

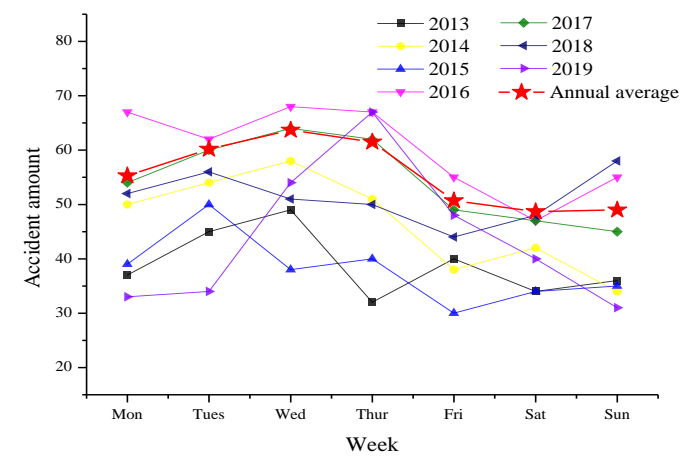

Fig 3: Weekly characteristics of accidents

ISSN: 0010-8189

C) CONVERTER 2021

www.converter-magazine.info 
It can be seen from Figure 3 that in each week, the scale of highway transportation accidents for dangerous cargo increased an overall first and then declined.

From Monday, the number of dangerous cargo accidents during highway transportation increased gradually, reached its maximum value on Wednesday, and then gradually decreased. The number of highway transportation accidents for dangerous cargo on Saturday and Sunday was similar, and the number of accidents on Sunday had increased slightly. This is related to the production characteristics of China's chemical industry. Most of hazardous chemicals production enterprises implement a weekly break system, and the demand for hazardous chemicals on Saturdays and Sundays is relatively low. Therefore, this has led to a corresponding reduction in the total amount of highway transportation of dangerous cargo and transportation accidents near the weekend.

Divided the day into 12 periods, each 2 hours is a period. Counting the time periods of 2,078 highway transportation accidents of dangerous cargo, the distribution map of the highway transportation accident amount of dangerous cargo in different periods are obtained.

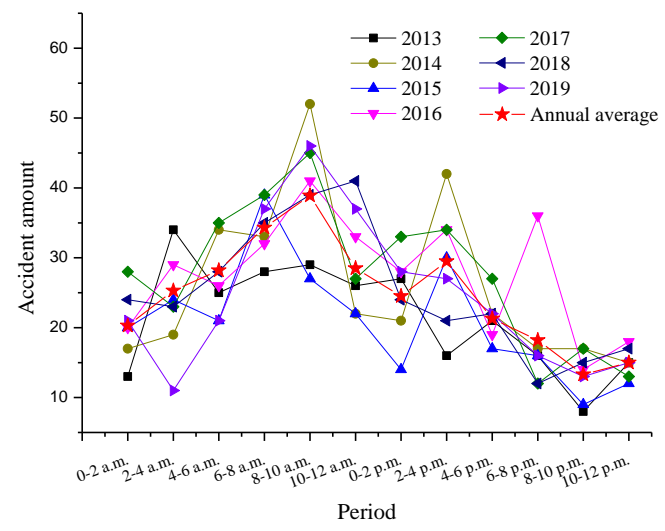

Fig 4: Period characteristics of accidents

As shown in figure 4, the trend for highway transportation accident amount of dangerous cargo was an irregular ' $\mathrm{M}$ ' type. The minimum of highway transportation accidents of dangerous cargo per day was 11 th period, and then the number of highway transportation accidents of was increasing. In fifth period, the accident amount of dangerous cargo reached the maximum and then gradually declined. Although, the number of dangerous cargo accident suddenly increased in the eighth period, then declined until reached the minimum at20:00-22:00. The trucks are barred from the most cites area during the period of 8:00-22:00, especially the transport vehicles for hazardous materials. Therefore, most dangerous cargo transport vehicles are shipped in the afternoon and enter and leave the city in the evening. However, the poor driving environment at night and the fatigue state of drivers and detainees after the morning are easy to cause an accident of dangerous cargo. During the period of 8:00-10:00, the conflict between the highway transportation of dangerous cargo and the morning rush hour of daily traffic is also easy to cause a traffic accident, so the accidents in this period are the most. From 14:00 to 16:00, a small peak of highway transportation accidents of dangerous cargo may occur because the driver is prone to fatigue driving in the afternoon.

Therefore, dangerous cargo accidents during highway transportation are easily affected by highway transportation safety supervision, holidays and unsafe driving behavior.

4.2 Location characteristic of accidents

ISSN: 0010-8189

C CONVERTER 2021

www.converter-magazine.info 
According to the different provincial administrative regions, road levels and road sections where the highway transportation accidents of dangerous cargo occurred, 2335 accidents were classified and counted, and the location characteristics of dangerous cargo accidents during highway transportation were obtained (see Figure 5 to Figure 7).

According to the statistics of highway transportation accidents of dangerous cargo in 34 provincial administrative regions of China in recent years, the distribution of highway transportation accidents of dangerous cargo in national administrative regions was divided into 8 levels.

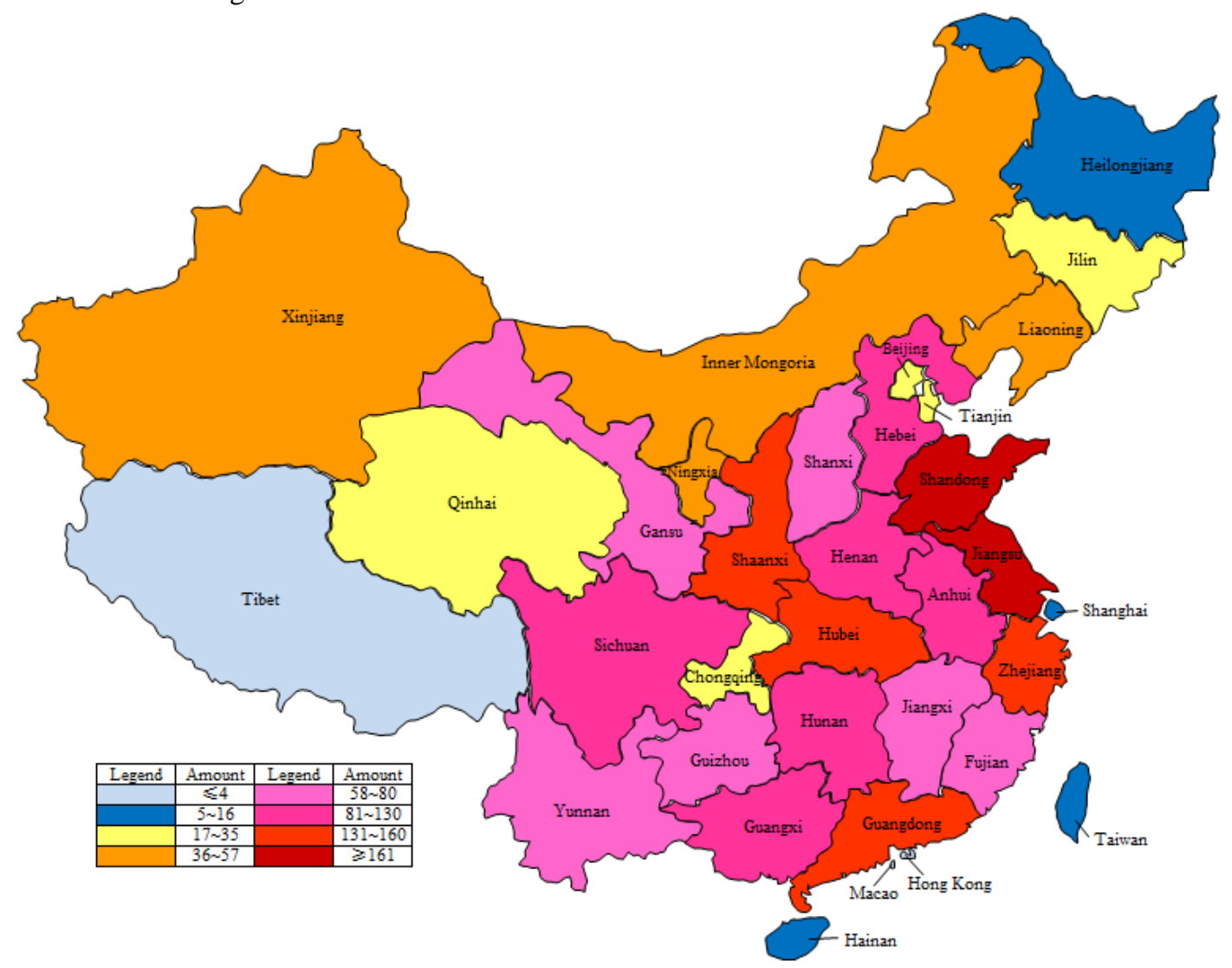

Fig 5: Provincial administrative region characteristics

It can be seen from the figure that in recent years, the administrative region with the largest number of highway transportation accidents of dangerous cargo in the mainland of China was Shandong, with a total of 218 accidents, followed by Jiangsu and Shaanxi, with 187 and 155 accidents, respectively. Tibet had the least number of highway transportation accidents of dangerous cargo in the mainland, with only one case, followed by Hainan and Qinghai, respectively, 15 and 16. Highway transportation accidents of dangerous cargo in Hong Kong and Macao had not been reported, and four highway transportation accidents of dangerous cargo had occurred in Taiwan in recent years. The reasons lie in the short-distance transport for highway transportation dangerous cargo. Therefore, the accident amount had a positive relationship with dangerous chemicals manufacturers. Shandong and Jiangsu had the much more hazardous chemicals production enterprises, with 2733 and 2425 respectively, but Tibet had only six, which is the least among the provincial administrative region (http://www.sohu.com/a/141663572_813316). In addition, the road sections of highway transportation accidents of dangerous cargo were uncertain. The statistical analysis of 2291 highway transportation accidents of dangerous cargo occurred in four different sections, including normal driving section, road intersection, bridge and tunnel section and parking area.

ISSN: 0010-8189

C CONVERTER 2021

www.converter-magazine.info 


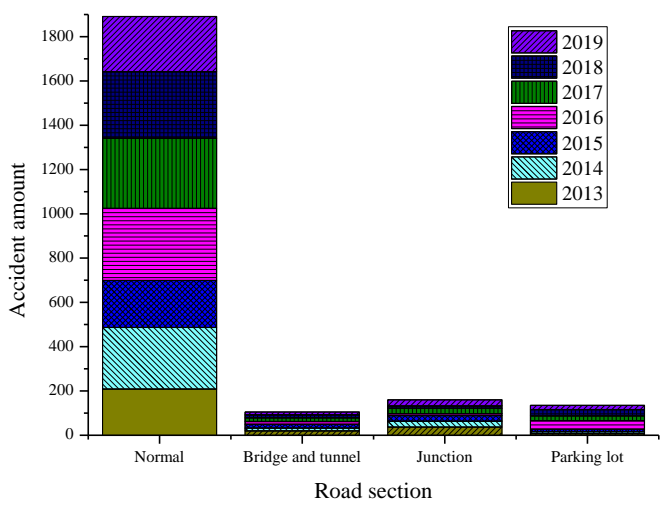

Fig 6: Road section characteristics of accidents

As shown in Figure 6, the dangerous cargo accidents during highway transportation occurred most in the normal driving sections, with a total of 1891 accidents, accounting for $82.52 \%$ of the total accidents, followed by road intersections and parking areas, respectively, 160 and 135, account for $7 \%$ and 5.9\%. The dangerous cargo accidents occurred on bridge and tunnel sections where is the least, with only 105 , accounting for $4.58 \%$ of the total accidents.

\subsection{Temperature at maximum pore pressure}

Combined with the data of highway transportation accidents of dangerous cargo from 2013 to 2019, according to the phase state of dangerous chemicals and the type of accident consequence, the highway transportation accidents of dangerous cargo were analyzed, and the data with unknown records and inconvenient classification were excluded. The consequences characteristics of phase state for dangerous cargo in accidents were obtained.

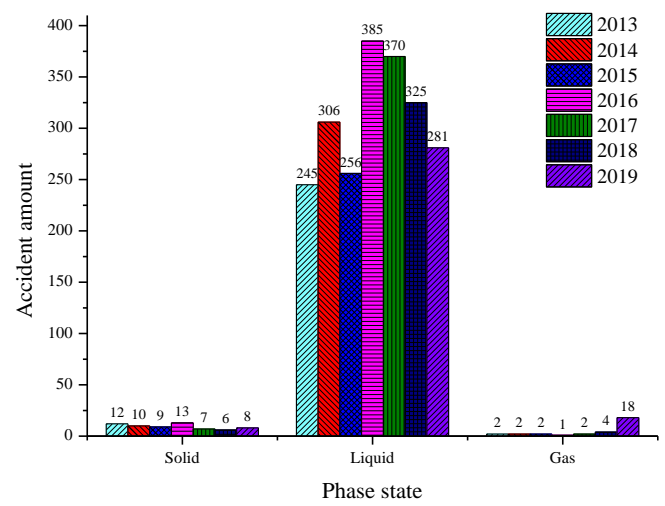

Fig 7: Phase state characteristics of accidents

As shown in Figure 7, in 2264 highway transportation accidents of dangerous cargo, the number of liquid dangerous cargo accidents was the largest, with 2168, accounting for $95.76 \%$ of the total number of accidents. Secondly, there were 65 solid dangerous cargo accidents, accounting for $2.87 \%$ of the total accidents. The amount of liquid dangerous cargo accidents was the least, only 31 , accounting for $1.37 \%$.

ISSN: 0010-8189

(C) CONVERTER 2021

www.converter-magazine.info 


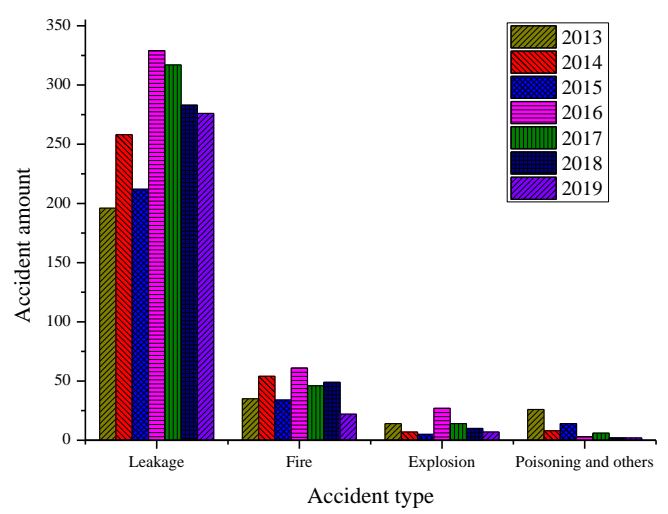

Fig 8: Subsequent events of accident

As shown in Figure 8, the subsequent events of 2317 dangerous cargo accidents were counted. There were 1871 leakage events, accounting for $80.75 \%$ of the total number of accidents. 301 accidents caused the fire event, accounting for $12.99 \%$ of the total. There were 84 explosion events, accounting for $3.63 \%$ of the total accidents. The number of accidents leading to poisoning and other consequences was the least, only 61, accounting for $2.63 \%$ of the total number of accidents.

\section{Results and Discussion}

According to the characteristics of dangerous cargo accidents during highway transportation in China from 2013 to 2019, the following countermeasures and suggestions are put forward.

1) In view of the obvious characteristics that the safety situation of highway transportation for dangerous cargo is obviously intervened by administrative supervision. It is much necessary to start from the safety production management for highway transportation enterprises of dangerous cargo and the safety supervision and management of highway transportation of dangerous cargo. On the one hand, it needs to strengthen the work safety responsibility of dangerous cargo highway transportation enterprises, for improving the safety management level of enterprises, and realizing the safety culture and consciousness change from ' Ask me to be safety '. On the other hand, with a high hand of safety supervision for the highway transportation of dangerous cargo, it should adopt effective classification and grading supervision methods to gradually improve the level of safety supervision.

2) According to the time distribution characteristics of dangerous cargo accidents during highway transportation, there are also at least three ways dangerous cargo transportation enterprises can improve safety in the transport industry. Firstly, specific prevention measures for the accident should be implemented while in the high-incidence period of accidents. For example, it is an effective measure to held preproduction meeting before the highway transportation. Furthermore, safety propaganda and education are important means of preventing and controlling dangerous cargo accidents. In addition, the safety department of dangerous cargo transportation enterprise can take real-time control and distance supervision controlling of drivers, to avoid the unsafe behaviors.

3) According to the spatial distribution characteristics of dangerous cargo accidents during highway transportation, provinces with high incidence of accidents need to strengthen the supervision and enforcement of highway transportation safety. For in-stance, using advanced technologies such as 5G and the IOT to strengthen the realtime monitoring and early warning of dynamic risks in the transport process is an effective measure to improve the intrinsic safety level of highway transportation of dangerous cargo. In addition, the highway transportation enterprises of dangerous cargo should strengthen the safety management and emergency intervention in the

ISSN: 0010-8189

C CONVERTER 2021

www.converter-magazine.info 
transportation link, and prevent the fatigue driving behavior of the normal driving section, so as to reduce the probability of accidents of highway transportation of dangerous cargo in the normal driving section.

4) Combined with the consequence characteristics of dangerous cargo accidents during highway transportation, safety supervision in the process of highway transportation of liquid dangerous cargo is the top priority. In view of the frequent occurrence of liquid dangerous cargo leakage accidents, it is necessary to work together to improve the accident response ability, in order to quickly and effectively control the development of dangerous cargo highway transportation accidents. Dangerous cargo transport vehicles should be equipped with common plugging tools and equipment. Drivers should have corresponding emergency procedures. Emergency rescue teams should be equipped with necessary transit equipment, materials and personal protective equipment. Rescue personnel should master scientific and effective emergency response methods.

Although dangerous cargo accident happened at the bridge and tunnel infrequently, it is necessary to pay attention to the serious consequences. Similarly, inter section is an important location where the accident can lead to many deaths and injuries.

\section{Conclusion}

Based on the data of highway transportation accidents of dangerous cargo from 2013 to 2019, the time characteristics and location characteristics and consequences characteristics for dangerous cargo accidents during highway transportation are obtained.

1) Since 2013, the scale of highway transportation accidents of dangerous cargo in China has shown an irregular ' $M$ ' distribution within a certain range of fluctuations. February is the month when there are fewer highway transportation accidents of dangerous cargo. The accident amount remains at a high level between March and August. The number of highway transportation accidents for dangerous cargo is the most in December. Beginning every Monday, the number of highway transportation accidents for dangerous cargo gradually increased every day, reaching the maximum on Wednesday. From the perspective of daily time distribution, the highway transportation accidents for dangerous cargo occur most frequently at fifth period every day.

2) In 31 provincial administrative regions (excluding Hong Kong, Macao, and Tai-wan), the top three highway transportation accidents of dangerous cargo are Shandong, Jiangsu and Shanxi. Tibet has the least highway transportation accidents of dangerous cargo. The highway transportation accidents of dangerous cargo occurred in the normal driving section the most, and the accidents in the bridge and tunnel section were the least. The highway transportation accidents of dangerous cargo occurred in the bridge and tunnel section the least.

3) The accidents of liquid dangerous cargo are the most frequent highway transportation accidents of dangerous cargo. Highway transportation accidents of dangerous cargo have the most leakage consequences, followed by fires.

4) Combining the characteristics of the highway transportation system of dangerous cargo, and according to the analysis results of the temporal and spatial distribution characteristics of dangerous cargo accidents during highway transportation, the targeted measures and suggestions for preventing and reducing highway transportation accidents of dangerous cargo are proposed.

\section{Acknowledgements}

This work was supported by the Scientific Research Foundation of Hunan Provincial Education Department (Grant No. 18B210).

ISSN: 0010-8189

(C) CONVERTER 2021

Www.converter-magazine.info 


\section{References}

[1] J. Cao, S.L. Shi, Y. Lu, et al., "Analysis on tank transportation accidents of hazardous chemicals from 2013 to 2018," China Safety Science Journal, vol. 30, pp. 119-126, 2020.

[2] Z.F. Zou, B.Q. Zhang, "Research status and development trend of hazardous materials transportation safety management," China Safety Science Journal, vol. 21, pp. 129-134, 2011.

[3] Y. Liu, L.S. Fan, X. Li, et al., "Trends of hazardous material accidents (HMAs) during highway transportation from 2013 to 2018 in China," Journal of Loss Prevention in the Process Industries, vol. 66, pp. 104150, 2020, https://doi.org/ 10.1016/j.jlp.2020.104150.

[4] G.H. Antoine, K. Sigon, S. Raja, "Characteristics of hazardous material accidents in Pennsylvania," Journal of Transportation Engineering, vol. 119, pp. 226-238, 1993, https://doi.org/10.1061/(ASCE)0733-947X(1993)119:2(226)

[5] B. Fabiano, F. Currò, E. Palazzi, et al, "A framework for risk assessment and decision-making strategies in dangerous good transportation,” Journal of Hazardous Materials, vol. 93, pp. 1-15, 2002, https://doi.org/10.1016/S0304-3894(02)00034-1

[6] J. Taboada, J.M. Matias, A. Saavedra, et al., "Neural network models for assessing road suitability for dangerous cargo transport," Human and ecological risk assessment, 12, (2006): 174-191, https://doi.org/1080-7039(2006)12

[7] B. Inanloo, B. Tansel, "A transportation network assessment tool for hazardous material cargo routing: Weighing exposure health risks, proximity to vulnerable areas, delay costs and trucking expenses," Journal of Loss Prevention in the Process Industries, vol. 40, pp. 266-276, 2016, https://doi.org/10.1016/j.jlp.2016.01.002

[8] J. Hong, R. Tamakloe, D. Park, "Application of association rules mining algorithm for hazardous materials transportation crashes on expressway," Accident Analysis \& Prevention, vol. 142, pp. 105497, 2020, https://doi.org/10.1016/j.jlp.2016.01.002

[9] J. Janno, O. Koppel, "Human factor as the main operational risk in dangerous cargo transportation chain," Business Logistics in Modern Management, vol. 17, pp. 63-78, 2016, https://doi.org/10.1016/j.jlp.2016.01.002

[10] Imeri, Adnan, D. Khadraoui, "The Security and Traceability of Shared Information in the Process of Transportation of Dangerous Goods," 2018 9th IFIP International Conference on New Technologies, Mobility and Security (NTMS), France, 2018, pp. 26-28, Publisher: IEEE, Paris, France, https://doi.org/10.1109/NTMS.2018.8328751

[11] I. Benekos, D. Diamantidis, "On risk assessment and risk acceptance of dangerous cargo transportation through road tunnels in Greece," Safety Science, vol. 142, pp. 1-10, 2017, https://doi.org/10.1016/j.ssci.2016.07.013

[12] L. Zhan, "Analytic study on transportation accidents of dangerous chemicals from 2006 to 2007 ," Journal of Safety Science and Technology, vol. 4, pp. 74-78, 2008.

[13] Z.Z. Wu, S.Z. Zhang, Y. Zhang, et al., "Statistical analysis of hazardous chemicals accidents occurring in China during 2006- 2010," Journal of Safety Science and Technology, vol. 7, pp. 5- 9, 2011.

[14] S.Y. Shen, X.N. Li, P. Xie, et al. "Statistical analysis on 886 road HAZMAT transportation accidents by the tank truck," Journal of Safety Science and Technology, vol. 8, pp. 43- 48, 2013.

[15] X.Y. Chen, S.L. Shi, J.Z. Ren, et al. "Statistical analysis and countermeasure research on the traffic accident of road dangerous chemicals from 2013 to 2014 in country," Journal of Hunan University of Science \&Technology( Natural Science Edition), vol. 32, pp. 91-95, 2017.

ISSN: 0010-8189

C CONVERTER 2021

www.converter-magazine.info 